\title{
BMJ Open Cohort profile: the vitamin A and D and nitric oxide (AD-ON) observational cohort on lung development and symptoms in premature and mature children in North Zealand, Denmark
}

\author{
Fanny Edit Maria Goth (D) ,,2 Birgitte Johanne Schmidt (1) , ${ }^{3}$ Klaus Juul, ${ }^{4}$ \\ Per Albertsen, ${ }^{1}$ Lone Agertoft, ${ }^{5}$ Inger Merete Jørgensen ${ }^{1,2}$
}

To cite: Goth FEM, Schmidt BJ, Juul K, et al. Cohort profile: the vitamin $A$ and $D$ and nitric oxide (AD-ON) observational cohort on lung development and symptoms in premature and mature children in North Zealand, Denmark. BMJ Open 2022;12:e054952. doi:10.1136/ bmjopen-2021-054952

- Prepublication history and additional supplemental materia for this paper are available online. To view these files, please visit the journal online (http://dx.doi.org/10.1136/ bmjopen-2021-054952).

Received 29 June 2021 Accepted 03 February 2022

D Check for updates

(c) Author(s) (or their employer(s)) 2022. Re-use permitted under CC BY-NC. No commercial re-use. See rights and permissions. Published by BMJ.

For numbered affiliations see end of article.

\section{Correspondence to} Dr Inger Merete Jørgensen; inger.merete.joergensen@ regionh.dk

\section{ABSTRACT}

Purpose The risk of developing asthma-like symptoms and asthma in childhood is influenced by genetics, environmental exposures, prenatal and early postnatal events, and their interactions. The cohort name refers to vitamins $A$ and $D$, and nitric oxide (NO) spelt backwards and this cohort profile paper aims to present the data collection and aim of the cohort.

The overall aim when establishing this cohort was to investigate if childhood lung function can be traced back to early neonatal lung function and fractional exhaled NO (FeNO) and investigate prenatal and postnatal risk factors including maternal and neonatal vitamin A and D levels in preterm and term born children.

Participants One thousand five hundred women and their babies born at Nordsjaellands Hospital in Denmark from 2013 to 2014 were included in the AD-ON research biobank prior to birth.

Neonates from the AD-ON research biobank, admitted to the Neonatal Intensive Care Unit at Nordsjaellands Hospital, were included in the AD-ON neonatal cohort. The neonatal cohort consisted of 149 neonates hereof 63 preterm and 86 term born. The children in the cohort have been invited to follow-up visits at age 1 and 6 years.

Findings to date Published data from this cohort includes a validated and clinically applicable method to measure FeNO in neonates. We found an age-specific pattern of association between respiratory symptoms at age 1 and neonatal FeNO in preterm children. Moreover, we found that the respiratory symptoms risk was associated with postnatal factors (Respiratory Syncytial Virus infection and parental smoking) in preterm infants and prenatal factors (parental asthma and maternal infection during pregnancy) in term born infants.

Future plans In the future, the children will be examined continuously with 3-year to 5-year intervals until the age of 18. Lung function, allergy tests, environmental exposure measurements and questionnaires will be collected at each follow-up visit.

\section{INTRODUCTION}

The overall aim of this cohort is to illuminate lung function development and risk factors

\section{Strengths and limitations of this study}

- The strengths of this cohort are the inclusion of both preterm and term born children, allowing for comparison between the groups.

- The prospective and longitudinal fractional exhaled nitric oxide (FeNO) and tidal breath measurements and the method validation on neonatal FeNO with a low subject-specific-prediction variance and high success rate of the method in neonates give us reliable and robust neonatal baseline data for this cohort.

- The data collected from this cohort include detailed prenatal and postnatal data from medical records, questionnaires and clinical observations by a trained physician.

- Limitations include the relatively small cohort and the risk of losing attendance at follow-up visits due to long intervals between visits and, in the case of the 6-year follow-up, the ongoing COVID-19 pandemic. This effect is expectedly minimised in the years to come.

for later respiratory diseases in children born preterm and at term. We hypothesised that the adult lung function can be traced back to early neonatal lung function and neonatal fractional exhaled nitric oxide (FeNO) and that prenatal and postnatal risk factors including but not exclusively maternal and neonatal vitamin $\mathrm{A}$ and $\mathrm{D}$ levels are predictive of future lung function and respiratory morbidity.

Respiratory diseases such as asthma, pneumonia and bronchiolitis are the most common reasons for hospitalisation in the paediatric population. ${ }^{1}$ The risk of developing asthmalike symptoms and asthma is influenced by the interaction of genetic disposition, environmental exposures and prenatal and early postnatal events. ${ }^{23}$ It is known today that 
the lung function you acquire in childhood predicts the adult lung function and, accordingly, the potential risk of developing chronic obstructive lung disease. ${ }^{4}$

An increasing number of extreme and early preterm infants survive today due to advanced prenatal and antenatal treatment. However, less research has focused on the long-term pulmonary outcomes of the largest preterm group, the moderate-to-late preterm born children. ${ }^{56}$ Children born preterm (before 37 weeks of gestation) have a lower lung function and a higher incidence of airway diseases than children born at term during infancy, childhood and adulthood; however, findings are conflicting when examining moderate-to-late preterm born children. ${ }^{7-11}$

Nitric oxide (NO) has multiple physiological functions in the inflammatory processes, angiogenesis and neonatal lung development. ${ }^{12}$ The role of NO in lung development is still being explored. NO is produced in the cells by different types of NO synthetases (NOS). NO is the main vasodilator in the transition from fetal to postnatal breathing. ${ }^{13}$ During fetal development, the expression of endothelial NOS increases in lung tissue. ${ }^{14}$ It has been proposed that this increase in NOS expression may enhance angiogenesis and respiratory function in the postnatal period. ${ }^{14}$ The use of exhaled NO (eNO) has expanded in pulmonology in recent years, both as a diagnostic tool and as an indicator of treatment response. ${ }^{15-18}$ However, the use of neonatal eNO shows conflicting results and validated applicable methods for measuring eNO in neonates are lacking. ${ }^{18} 19$

FeNO and tidal breathing parameters can be measured simultaneously and without risk in non-sedated neonates, making it clinically applicable from the first days of life. Previous studies have examined $\mathrm{FeNO}$ and tidal breathing parameters in early preterm (gestational age $(\mathrm{GA})<32$ weeks) neonates during the first days of life. ${ }^{20-23} \mathrm{Few}$ studies have examined FeNO and neonatal lung function in moderate-to-late preterm infants from the first days of life. To our knowledge, none of these studies have longitudinal data in infancy and childhood. However, longitudinal data from 1-month-old in term born infants have been presented earlier. ${ }^{18} 24$

The transplacental transfer of vitamins occurs primarily during the last trimester. Therefore, preterm neonates generally have low levels of vitamins and minerals. ${ }^{25}{ }^{26}$ Furthermore, vitamin A consumption is exceptionally high during the last trimester and shortly after birth due to its role in lung maturation. ${ }^{26}$ Vitamin $\mathrm{D}$ has been shown to increase surfactant production in the rat fetus. ${ }^{27}$ It is involved in the interaction between epithelium and mesenchyme during lung growth and inhibits smooth muscle proliferation in the airways. ${ }^{28} \mathrm{~A}$ low level of vitamin D during pregnancy is associated with recurrent wheeze in early childhood. ${ }^{29} 30$

The name of this cohort refers to vitamins $\mathrm{A}$ and $\mathrm{D}$ plus nitric oxide (NO) spelt backwards. When the cohort was first established, the primary aim was to assess and validate the feasibility of clinical measurement of FeNO in neonates in an unselected group of preterm and term born infants. We measured lung function and $\mathrm{FeNO}$ longitudinally and collected biological samples (ie, blood) from birth into childhood in preterm and term born children. We started by developing a validated method for neonatal FeNO measurement and in our further work on the cohort we are using these data to explore the association between neonatal measurements as well as risk factors, including genes, and prenatal, perinatal and postnatal events, environmental exposure, and their interactions with lung function and respiratory morbidity later in life. By doing this, we expect to identify biomarkers and to evaluate the role of vitamins $\mathrm{A}$ and $\mathrm{D}$ for subsequent respiratory symptoms and lung disease, as well as illuminating lung function development in moderate-tolate preterm and term born children.

This paper describes the recruitment, inclusion and data collection in the AD-ON research biobank and AD-ON neonatal cohort.

\section{COHORT DESCRIPTION}

\section{Recruitment and inclusion in the cohort}

All women ( $\mathrm{n}=2700)$ who planned to give birth at Nordsjaellands Hospital, Denmark, from September 2013 to September 2014 were invited to participate in the AD-ON research biobank. One thousand five hundred infants and mothers were included prior to birth.

The parents of infants included in the AD-ON research biobank and subsequently admitted to the neonatal intensive care unit (NICU) at Nordsjaellands Hospital, Denmark, were invited to participate in AD-ON neonatal cohort.

Criteria for inclusion in the AD-ON neonatal cohort were: inclusion in the AD-ON research biobank, admission to the NICU within the first 7 days of life, at least one parent able to read and understand Danish, and an informed consent form signed by both parents. Exclusion criteria were known congenital pulmonary or heart disease.

The sample size for the AD-ON neonatal cohort was based on data from earlier studies where neonatal FeNO was used to differentiate between healthy and sick neonates. Due to a lack in previous research investigating the long-term predictive value of neonatal $\mathrm{FeNO}$ when the cohort was established, we chose to use data from a study investigating differences in neonatal FeNO between healthy neonates and neonates who developed bronchopulmonary dysplasia (BPD).$^{31}$ We sought to show a difference in FeNO of $3.1 \mathrm{ppb}$ (SD 2.0) (minimal relevant difference $=1.55 \mathrm{ppb})^{31}$ between groups with the power of $80 \%$ and a significance level of 0.05 . The calculation was performed on the most relevant groups and extrapolated to the other groups. The sample size was calculated using a two-sample t-test in R software (V.3.5.2; https://www.rproject.org/), resulting in a sample size in each group of $\mathrm{N}=8$ neonates. The groups were defined as (1) GA $<28$ weeks, (2) GA 28-32 weeks, (3) GA 32-34 weeks, (4) GA 
35-37 weeks and (5) GA >37 weeks and each subgroup further into two groups (healthy/disease), making it a total of 10 groups.

Additionally, in the literature, it is recommended to include 12 patients in each subgroup for method validations and pilot studies. ${ }^{32-34} \mathrm{We}$, therefore, chose to include 120 neonates $(\mathrm{N}=12 \times 10$ subgroups $)$ plus 30 neonates (due to an expected dropout rate of $20 \%$ ), which added up to 150 infants.

Due to experience from previous years, we expected that approximately $10 \%$ of the newborns would be admitted to the NICU and, therefore, included 1500 mother-infant pairs in the AD-ON research biobank.

Furthermore, we expected a higher incidence of respiratory symptoms in childhood in the term born children in our cohort compared with the background population (due to the inclusion criteria being admission to the NICU) were the prevalence of asthma symptoms at age 5 is approximately $20 \% .{ }^{35}$ Earlier studies have found that the difference in prevalence of wheeze or asthma between preterm and term born children are between $5 \%$ and $20 \% .^{9637}$ To be able to show a difference in the prevalence of respiratory symptoms in childhood between preterm and term born children with a power of $80 \%$ and significance level of 0.05 we needed 62 children in each group (preterm vs term).

One hundred seventy-nine of the 1500 neonates included in the AD-ON research biobank were admitted to NICU within the first 7 days of life. Of these, 149 fulfilled the inclusion criteria and were included in the AD-ON neonatal cohort. However, the included infants did not distribute into GA groups as expected in the sample size calculation. Therefore, the cohort has been divided into only two subgroups (preterm and term born) in most analysis.

\section{Visits and follow-up}

Neonates in the AD-ON neonatal cohort were scheduled for visits at postnatal days 2-3, 5, 7, 14, 21 and 28 in 2013-2014. Preterm infants had an extra visit at GA 36 weeks. The cohort was invited to a follow-up visit in 20142015 at the age of 1 year. Of the 149 neonates included, 146 were available for follow-up. A questionnaire was collected from 135 families; 112 families attended a clinical follow-up visit (figure 1). The cohort was invited to a second follow-up visit at age 6-7years in years 2019-2021. Data from 6-year follow-up are yet to be published. Hereafter, the plan is to continuously follow the children with 3-year to 5-year intervals until age 18. At each follow-up, lung function testing, allergy tests, questionnaires on respiratory symptoms and general health, as well as samples of blood, urine, stool and hair to investigate longterm environmental exposures, will be collected.

\section{Data collection}

\section{AD-ON research biobank cohort}

Blood samples were collected from the mother and the umbilical cord by needle puncture (covered to prevent

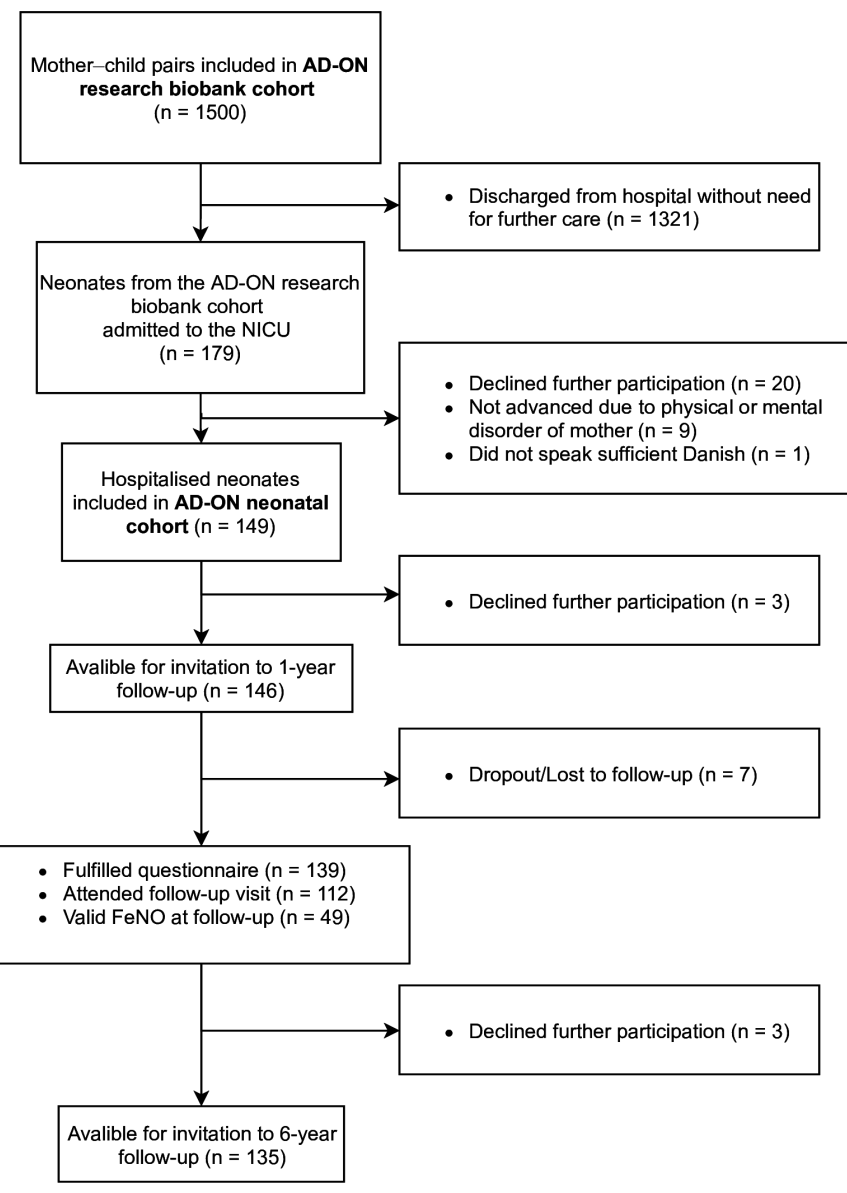

Figure 1 Flow chart showing the inclusion and exclusion of participants in the AD-ON neonatal cohort from birth to 6 years of age. FeNO, fractional exhaled nitric oxide; NICU, neonatal intensive care unit.

a reaction with light) immediately after birth and separated after centrifuging as serum, EDTA plasma and buffy coat. All samples were frozen at $-80{ }^{\circ} \mathrm{C}$ within 4 hours for quality reasons. Plasma calcium was included in the routine blood samples at NICU and immediately analysed; results were entered into the database. The frozen samples are kept anonymously in the research biobank until analysis.

\section{AD-ON neonatal cohort \\ Baseline data}

At the NICU unit, medical history and medical records of mothers and neonates were reviewed. Detailed information on maternal health status, ultrasound findings during pregnancy, fetal growth data and diagnoses were collected and entered in the database. Parents were also interviewed systematically to gather further information on health, social status and lifestyle.

Baseline data include: maternal ethnicity, maternal age, weight gain in pregnancy, maternal blood pressure, maternal diabetes, parental asthma, allergy or/and eczema, parental smoking, parental alcohol use, social group and postal code of parents at delivery, maternal infections during pregnancy, hyperemesis during pregnancy, intrauterine infections, chorioamnionitis, preeclampsia, 
maternal medication use, rupture of membranes, colour of amniotic fluid, amount of amniotic fluid (normal/ polyhydramnion/oligohydramnion/no amniotic fluid), antenatal steroid, antibiotics during labour, sex, GA, day and time of birth, delivery mode, birth weight, small for gestational age at birth, birth length, head circumference at birth, single/multiple pregnancy, APGAR score at 1 and $5 \mathrm{~min},{ }^{38}$ age of APGAR=10, age at first breath, resuscitation needed at birth, $\mathrm{FiO}_{2}$ in the delivery room, continuous positive airway pressure (CPAP) at birth, intubation, umbilical cord blood sample (base excess, $\mathrm{pH}$ and $\mathrm{pCO}_{2}$ ), placenta weight, placenta pathology, hours to first meconium, respiratory frequency and symptoms at admission to NICU, fontanelle size (normal or large), capillary blood samples 2 hours after birth $\left(\mathrm{pH}, \mathrm{pCO}_{2}\right.$, $\mathrm{pO}_{2}$, bicarbonate, blood glucose, base excess).

\section{Clinical data and data from medical records}

A trained physician performed a complete physical examination on all infants in the cohort at every visit. During admission at the NICU, daily respiratory symptoms, clinical and vital parameters were collected prospectively to the database. Two different research assistants double checked all data entries.

Anthropometric parameters include weight, height and head circumference. Weight was measured with SECA model 376 on neonates and at 1-year follow-up and 6-year follow-up with SECA model 769. The results were recorded in $\mathrm{kg}$ with two decimals. In neonates and at 1-year follow-up, the length was measured with SECA model 207, and at 6-year follow-up, height was measured with SECA model 216. Head circumference was measured with a measuring tape three times, and the highest value was recorded in $\mathrm{cm}$ with one decimal.

Blood pressure, pulse and oxygen saturation were measured with Sure Signs vs2+ (ViCare Medical) at the 6-year follow-up.

Clinical neonatal data include CPAP treatment (start and stop dates and maximum pressure), treatment with caffeine citrate, treatment with surfactant (and any medication in relation to this administration), neonatal infection (including date of infection, core temperature, and results of bacterial culture), respiratory symptoms during admission, antibiotic treatment, postnatal corticosteroid treatment, jaundice (including plasma bilirubin level and treatment), need for parenteral nutrition, the start of enteral nutrition, age when daily nutritional need were met enterally (formula or breast milk), vitamin supplements, diagnose of BPD, ICD-10 diagnosis at discharge, days of hospitalisation after birth, GA at discharge, number of hours with a need for supplemental oxygen (including maximum $\mathrm{FiO}_{2}$ given).

Any other examination or treatment clinically indicated during admission at the NICU was registered, including results of ultrasonic investigation of the brain, echocardiography, examining retinopathy of prematurity (only neonates born before 32 weeks of gestation), and blood transfusion.
Data on hospital admissions, ICD-10 diagnoses, given medicine and vaccinations ${ }^{39}$ were after permission by the parents, collected from the medical records.

\section{Questionnaires}

At 1-year follow-up, parents answered a questionnaire on the child's general health, focusing on respiratory and allergy symptoms, airway infections, use of asthma medication (inhaled beta2agonist, inhaled corticosteroid (ICS), leukotriene receptor antagonist), antibiotic treatment during the first year of life and hospital admissions.

At 6-year follow-up, questionnaires on the child's general health focused on respiratory and allergy symptoms, medication, and airway infections, as well as standardised questionnaires (International Study of Asthma and Allergy in Childhood (ISAAC) and Asthma Control Index), were distributed. ${ }^{40} 41$

\section{Biological samples and biobanking}

In addition to the umbilical cord blood collected, all neonates in the AD-ON neonatal cohort had blood samples drawn at postnatal days 2-3, 21 and at 1-year follow-up. Preterm neonates also had a blood sample drawn at GA 36 weeks. All these blood samples were stored in a biobank at $-80^{\circ} \mathrm{C}$ as described above.

At 6-year follow-up, we collected stool, urine and blood samples for biobank storage or immediate analysis. Stool samples were stored fresh-frozen at $-20{ }^{\circ} \mathrm{C}$ to ensure future microbiome analysis and, after that, moved to -80 ${ }^{\circ} \mathrm{C}$ freezers. ${ }^{42}$ Urine samples were stored at $-80{ }^{\circ} \mathrm{C}$ without prior handling. Some of the blood was analysed for $\operatorname{IgE}$ and eosinophil count. Buffy coat and EDTA plasma were stored in the biobank at $-80{ }^{\circ} \mathrm{C}$.

When collecting blood samples from neonates, infants and children, it is recommended not to exceed $10 \%$ of the expected total blood volume. ${ }^{43}$ The amount of blood collected in this study is far below this.

Hair samples collected are stored in sealed packaging at room temperature.

\section{FeNO measurements}

Online measurements of mixed tidal FeNO were performed on infants placed in their cribs or their parent's arms in a supine position during natural (often postprandial) sleep. Measurements were performed with Ecomedics CLD 88sp according to American Thoracic Society (ATS) /European Respiratory Society (ERS) standards. ${ }^{44}$ The FeNO analysis was performed at $60 \%-80 \%$ of the expired volume of each selected breath. The computer software automatically included breaths only if they fell within $10 \%$ variation of the mean tidal volume. The machine's minimal tidal volume was $10 \mathrm{~mL}$, and the time delay of the flow was $0.65 \mathrm{~s}$. A DENOX 88 device provided NO free air. The infants breathed through a silicone facemask without septum (Fisher\&Paykel Healthcare size $35-50 \mathrm{~mm}$ (XS-M)) covering both mouth and nose. The effective dead space of the mask was 5, 8 and $11 \mathrm{~mL}$, respectively. Every measurement was performed 
over $60 \mathrm{~s}$ at least three times to obtain three measurements with maximal FeNO deviance of 1 ppb. ${ }^{45}$

Measurements were performed on postnatal days 3, 5, 7, 14, 21 and 28, and again at 1-year follow-up. At the 6-year follow-up, FeNO was measured by single breath exhalation with Ecomedics CLD 88sp according to the ERS and the ATS guidelines. ${ }^{44}$

Calibration and maintenance of the device were performed following the guidelines of the manufacturer.

\section{Lung function measurements}

Tidal flow-volume parameters were measured simultaneously with FeNO measurements using the Ecomedics CLD 88sp (software Spiroware Client V.3.1.6) on days 3, $5,7,14,21,28$, and at 1 year. All measurements with a minimum of 10 consecutive flow-volume curves with a maximal variation in the tidal volume of $10 \%$ were visually examined. All curves with stable volume and shape were selected by visual examination, and from these curves, mean, SD and coefficient of variance were calculated for each measurement. ${ }^{46} 47$

At 6-year follow-up, multiple lung function tests were performed such as spirometry with reversibility for salbutamol (performed on Jæger IM PRO), resistance measurements by body plethysmograph (performed on Jaeger Master Screen Body), resistance and reactance measurements by impulse oscillation technique (performed on Jæger IOS, Vyntus) and diffusion capacity for carbon monoxide (performed on Jaeger SB Diffusion Real-Time adaptor for Master Screen Body). All measurements were performed using the SentrySuite software solution from Vyaire and according to the ERS and ATS standards. ${ }^{47-49}$ Calibration and maintenance of the devices were performed according to the manufacture's guidelines.

\section{Cardiac measurements}

At the 6-year follow-up, all participants were offered an ECG and transthoracic echocardiography to examine for pulmonary hypertension and structural cardiac abnormalities. ${ }^{50}$ Transthoracic echocardiograms were performed in accordance with recommendations from the American Society of Echocardiography. ${ }^{51}$

All echocardiographic parameters collected are presented in online supplementary table $\mathrm{E} 1$ and calculations in online supplementary table E2. A trained paediatric cardiologist performed the echocardiography using the EPIQ 5 ultrasound system (Philips). All images and measurements were by blinded method double checked by a senior paediatric cardiologist to ensure validity.

\section{Skin prick testing (SPT)}

Children and their biological parents were all offered an SPT for the positive and negative control, and the most common inhalation allergens (grass, birch, mugwort, house dust mites, mould fungi, dog, cat, and horse (all allergen extracts were purchased at ALK- Abelló A/S, Horsholm, Denmark)) at 6-year follow-up. The SPT was performed on clean and healthy skin, and it was made sure no medication that could affect the result had been taken before the SPT. The SPT was considered positive if the reaction size was larger than $3 \mathrm{~mm}$ (two measurements of size added and divided by 2 ).

For an overview of the data collection, see table 1.

\section{Outcomes at follow-up}

The outcomes at 1-year follow-up were troublesome respiratory symptoms (TRS) and asthmatic bronchitis (AB) during the first year of life. TRS was defined as wheeze or cough minimum twice a week for more than 2 months continuously and/or wheeze or night-time cough for a shorter period (2 weeks) more than three times a week during periods without respiratory infections. $\mathrm{AB}$ was defined as respiratory wheeze and cough in association with an airway infection. $\mathrm{AB}$ was the expression and diagnosis used in Denmark in 2013-2015 and corresponds to the more commonly used episodic viral wheeze. ${ }^{52}$

At the 6-year follow-up, the primary outcomes were doctor-diagnosed asthma or wheeze during the previous year.

At both follow-up visits, we defined the use of shortacting inhaled beta-agonist and ICS during the first year of life as surrogate measures for respiratory symptoms.

As secondary outcomes, we looked at hospitalisations due to respiratory problems, pneumonia treated with antibiotics, and atopic sensitisations defined as a positive skin prick test and/or positive IgE.

\section{Participant and patient involvement}

The study participants and their parents did not directly influence the study design and baseline data collection. However, the participants have shown a great interest in the project and willingness to answer questionnaires and attend follow-up visits.

\section{Precautions concerning the COVID-19 pandemic in 2020}

While we were completing the 6-year follow-up, the world was hit by the COVID-19 pandemic. This affected the follow-up, and many visits had to be postponed. For those visits that could take place, the setting was altered to ensure both children's, parents' and investigators' health and well-being. All necessary precautions were taken with appropriate social distancing, use of protective equipment and close personal contact was kept to a minimum, following regional recommendations at the time to minimise the risk of viral transmission. All children and parents should not show any signs of possible cold or fever at the time of the visit, and children also had to present a negative PCR COVID-19 test that was no older than 48 hours. During the pandemic, only one parent could accompany the child at the visit due to regional recommendations.

\section{Cohort characteristics}

More than $50 \%$ of all newborn babies at Nordsjaellands Hospital were enrolled in the AD-ON research biobank cohort during the 12-month inclusion period. Approximately $10 \%$ of the neonates in the AD-ON research biobank cohort were admitted to the NICU. The primary 
Table 1 Overview of data collection into 6 years of age in the AD-ON neonatal cohort

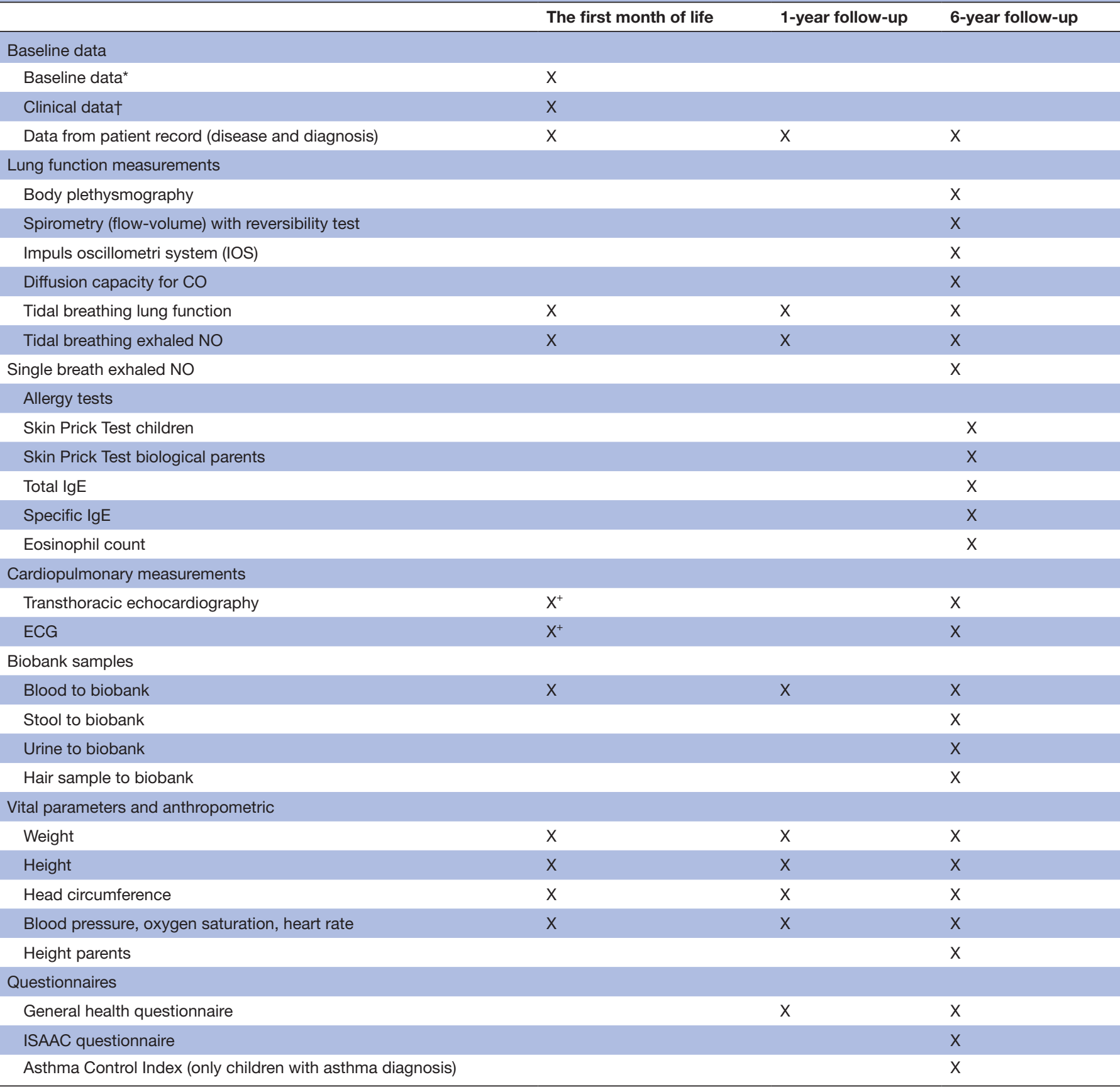

*Baseline data include: maternal ethnicity, maternal age, weight gain in pregnancy, maternal blood pressure, maternal diabetes, parental asthma, allergy or/and eczema, parental smoking, parental alcohol use, social group and postal code of parents at delivery, maternal infections during pregnancy, hyperemesis during pregnancy, intrauterine infections, chorioamnionitis, preeclampsia, maternal medication use, rupture of membranes, colour of amniotic fluid, amount of amniotic fluid (normal/polyhydramnion/oligohydramnion/no amniotic fluid), antenatal steroid, antibiotics during labour, sex, gestational age, day and time of birth, delivery mode, birth weight, small for gestational age at birth, birth length, head circumference at birth, single/multiple pregnancy, APGAR score at 1 and 5 min, age of APGAR $=10$, age at first breath, resuscitation needed at birth, $\mathrm{FiO}_{2}$ in the delivery room, continuous positive airway pressure (CPAP) at birth, intubation, umbilical cord blood sample (base excess, $\mathrm{pH}$ and $\mathrm{pCO}_{2}$ ), placenta weight, placenta pathology, hours to first meconium, respiratory frequency and symptoms at admission to $\mathrm{NICU}$, fontanelle size (normal or large), capillary blood samples 2 hours after birth ( $\mathrm{pH}, \mathrm{pCO}_{2}, \mathrm{pO}_{2}$ bicarbonate, blood glucose, base excess).

tClinical data from the admission at NICU were collected prospectively from the medical charts and include CPAP treatment (start and stop dates and pressure), treatment with caffeine citrate, treatment with surfactant (and any medication in relation to the administration), neonatal infection (including date of infection, core temperature and results of bacterial culture), respiratory symptoms during admission, antibiotic treatment, postnatal corticosteroid treatment, jaundice (including plasma bilirubin level and treatment), need for parenteral nutrition, the start of enteral nutrition, age when daily nutritional need fulfilled enterally (formula or breast milk), vitamin supplements, diagnose of bronchopulmonary dysplasia, ICD-10 diagnosis at discharge, days of hospitalisation after birth, gestational age at discharge, number of hours with a need for supplemental oxygen (including maximum $\mathrm{FiO}_{2}$ given).

¥Only if the clinician with treatment responsibility found it clinically indicated during the admission at the NICU.

NICU, neonatal intensive care unit; NO, nitric oxide. 


\begin{tabular}{|c|c|c|c|c|c|}
\hline Variable & & Preterm $(n=63)$ & Term $(n=86)$ & Total $(n=149)$ & $P$ value \\
\hline \multirow[t]{2}{*}{ Sex } & Male & $36(57.1)$ & $48(55.8)$ & $84(56.4)$ & \\
\hline & Female & 27 (42.9) & $38(44.2)$ & $65(43.6)$ & $>0.99$ \\
\hline \multirow[t]{2}{*}{ Delivery mode } & Vaginal delivery & $30(47.6)$ & $55(64.0)$ & $85(57.0)$ & \\
\hline & Caesarean section & $33(52.4)$ & $31(36.0)$ & $64(43.0)$ & 0.07 \\
\hline Birth weight (kg) & Mean (SD) & $2.165 .1(516.4)$ & $3.374(686.1)$ & $2.862 .8(860.9)$ & $<0.001$ \\
\hline Gestational age in days & Mean (SD) & $239(15)$ & $276.1(9.8)$ & $260.4(22.1)$ & $<0.001$ \\
\hline Twins & & $17(27.0)$ & $12(14.0)$ & $29(19.5)$ & 0.08 \\
\hline $\mathrm{SGA}^{*}$ & & $8(12.7)$ & $10(11.6)$ & $18(12.1)$ & 0.47 \\
\hline Parental asthma & & $17(27.0)$ & $14(16.3)$ & $31(20.8)$ & 0.17 \\
\hline Smoking during pregnancy & & $1(1.6)$ & $7(8.1)$ & $8(5.4)$ & 0.17 \\
\hline \multirow[t]{6}{*}{ Social group parents $†$} & 1 & $15(24.2)$ & $23(26.7)$ & $38(25.7)$ & \\
\hline & 2 & $14(22.6)$ & $25(29.1)$ & $39(26.4)$ & \\
\hline & 3 & $12(19.4)$ & $20(23.3)$ & $32(21.6)$ & \\
\hline & 4 & 16 (25.8) & 15 (17.4) & 31 (20.9) & \\
\hline & 5 & $5(8.1)$ & $3(3.5)$ & $8(5.4)$ & 0.48 \\
\hline & Missing & 1 & 0 & 1 & \\
\hline
\end{tabular}

${ }^{*}$ Small for gestational age (SGA) at birth $\left(<-2\right.$ SD of expected $\left.{ }^{58}\right)$.

†Social group parents (1) academics, self-employed in a large company, highest officials/white-collar workers, (2) persons with a medium-to-long academic education, self-employed in a medium to a large company, and high officials/white-collar workers, (3) self-employed in a smaller company and intermediate officials/white-collar workers, (4) subordinate official/white-collar workers and skilled professionals/blue-collar workers; and (5) unskilled/blue-collar workers.

reason for admission at the NICU was transient tachypnea of the newborn or respiratory distress in $48(32$ $\%)$, prematurity in $37(25 \%)$, small for GA in $16(11 \%)$, hypoglycaemia in $7(5 \%)$, sepsis in $6(4 \%)$, asphyxia in 6 $(4 \%)$, jaundice in $6(4 \%)$, weight loss in $2(1 \%)$, seizures in $1(0.5 \%)$ and other reasons that required observation at the NICU in 20 neonates $(13 \%)$.

In the AD-ON neonatal cohort, including 149 neonates, 86 were term born $(\mathrm{GA} \geq 37+0), 55$ moderate to late preterm (GA 32+6-36+6), and 8 were born very preterm (GA 28-32+6), for demographics and characteristics, see table 2.

At 1 year follow-up, questionnaires were collected from 139 infants, and 112 infants attended the follow-up visit (table 3). Thirty-two infants had TRS during the first year of life, and 25 were diagnosed with $\mathrm{AB}$ (table 4 ).

\section{Findings to date}

Published data on this cohort include a validated and clinically applicable method to measure FeNO and V'NO $\left(\mathrm{NO} \times\right.$ flow) in preterm and term born neonates. ${ }^{45}$ With this method, we also showed that measuring tidal FeNO in respiratory unstable infants can be performed during a short (minutes) pause from CPAP treatment. ${ }^{53}$ The study design and cohort allowed us to construct longitudinal neonatal tidal FeNO and V'NO reference charts for preterm and term born neonates. ${ }^{54}$ Other key findings include the change of longitudinal $\mathrm{FeNO}$ values with postnatal age. Prematurity altered the FeNO curve pattern compared with the pattern of term born infants. ${ }^{45}$ Based on data from this cohort, we have identified and suggested that prenatal, neonatal and environmental modifiers of FeNO and V'NO are age dependent and could depend on the antenatal or postnatal time of exposure.

Moreover, we found that postnatal age at measurement had a significant effect on the association between FeNO and respiratory symptoms at 1 year in moderate preterm infants (GA 32-34 weeks) $(\mathrm{p}=0.02)$ but not in late preterm (GA 35-37 weeks) or term born infants (GA $>37$ weeks $)(p=0.50$ and 0.29 , respectively). A high FeNO on postnatal day 3 was associated with a low risk of TRS compared with a high FeNO on postnatal day 14, which was associated with a high risk of TRS in moderate preterm infants. ${ }^{55}$ Preterm born infants did not have significantly more respiratory symptoms compared with term born infants at 1-year follow-up. ${ }^{55}$ Additionally, we found that TRS risk was associated with postnatal factors (RSV infection with OR 33.9, 95\% CI 4.2 to 794.4, $\mathrm{p}=0.005$ and parental smoking with OR 7.4, 95\% CI 2.1 to $30.5, \mathrm{p}=0.003$ ) in preterm born infants and prenatal factors (parental asthma with OR 4.9, 95\% CI 1.3 to 18.3, $\mathrm{p}=0.02$, and maternal infection during pregnancy with OR 3.7, 95\% CI 1.1 to $12.8, \mathrm{p}=0.03$ ) in term born infants. ${ }^{55}$ Noteworthy, parental asthma did not influence the TRS risk at 1 year old in preterm infants in our cohort.

\section{Strengths and limitations of this study}

The strengths of this cohort are the inclusion of both preterm and term born children, allowing for comparison 
Table 3 Characteristics of participants who answered the questionnaire at 1-year follow-up compared with those lost to follow-up or dropped out, N (\%)

\begin{tabular}{|c|c|c|c|c|c|}
\hline Variable & Level & Included 1 y FU (n=139) & $\begin{array}{l}\text { Dropout/lost to follow- } \\
\text { up } 1 \text { y FU }(n=10)\end{array}$ & Total $(n=149)$ & $P$ value \\
\hline \multirow[t]{2}{*}{ Sex } & Male & $80(57.6)$ & $4(40.0)$ & $84(56.4)$ & \\
\hline & Female & $59(42.4)$ & $6(60.0)$ & $65(43.6)$ & 0.45 \\
\hline \multirow[t]{2}{*}{ Delivery mode } & Vaginal delivery & $80(57.6)$ & $5(50.0)$ & $85(57.0)$ & \\
\hline & Caesarean section & $59(42.4)$ & $5(50.0)$ & $64(43.0)$ & 0.89 \\
\hline Birth weight (kg) & Mean (SD) & $2827.7(854.1)$ & $3350.5(847.7)$ & 2862.8 (860.9) & 0.06 \\
\hline \multirow[t]{2}{*}{ GA group } & Term & $80(57.6)$ & $6(60.0)$ & $86(57.7)$ & \\
\hline & Preterm & $59(42.4)$ & $4(40.0)$ & $63(42.3)$ & $>0.99$ \\
\hline Twins & & 29 (20.9) & $0(0.0)$ & 29 (19.5) & 0.23 \\
\hline $\mathrm{SGA}^{*}$ & & $18(12.9)$ & $0(0.0)$ & $18(12.1)$ & 0.44 \\
\hline \multirow{5}{*}{ Social group parents $\dagger$} & 2 & $36(26.1)$ & $3(30.0)$ & $39(26.4)$ & \\
\hline & 3 & $29(21.0)$ & $3(30.0)$ & $32(21.6)$ & \\
\hline & 4 & $29(21.0)$ & $2(20.0)$ & $31(20.9)$ & \\
\hline & 5 & $7(5.1)$ & $1(10.0)$ & $8(5.4)$ & 0.76 \\
\hline & Missing & 1 & 0 & 1 & \\
\hline
\end{tabular}

*Small for gestational age at birth $\left(<-2\right.$ SD of expected $\left.{ }^{58}\right)$.

†Social group parents (1) academics, self-employed in a large company, highest officials/white-collar workers, (2) persons with a medium-to-long academic education, self-employed in a medium to a large company, and high officials/white-collar workers, (3) self-employed in a smaller company and intermediate officials/white-collar workers, (4) subordinate official/white-collar workers and skilled professionals/blue-collar workers; and (5) unskilled/blue-collar workers.

between the groups. Many similar cohorts have either excluded preterm children or only included preterm children. $^{5657}$

The prospective and longitudinal FeNO and tidal breath measurements and the method validation on neonatal FeNO with a low subject-specific-prediction variance and high success rate of the method in neonates give us reliable and robust neonatal baseline data for this cohort. In addition, the data include detailed prenatal and postnatal data from medical records, questionnaires,

Table 4 Prevalence of troublesome respiratory symptoms and asthmatic bronchitis and use of asthma inhalation medication at 1-year follow-up, $\mathrm{N}(\%)$

\begin{tabular}{|c|c|c|c|c|}
\hline & Preterm $(n=59)$ & Term $(n=80)$ & Total $(n=139)$ & $P$ value \\
\hline $\mathrm{TRS}^{*}$ & $17(28.8)$ & 15 (18.8) & 32 (23.0) & 0.234 \\
\hline $\mathrm{AB} \dagger$ & $11(18.6)$ & $14(17.5)$ & 25 (18.0) & 1.000 \\
\hline SABA use 1 y§ & $13(22.0)$ & $19(23.8)$ & $32(23.0)$ & 0.973 \\
\hline LTRA use 1 yף & $1(1.7)$ & $0(0.0)$ & $1(0.7)$ & 0.878 \\
\hline Missing data pneumonia 1 y & 0 & 1 & 1 & \\
\hline Atopic dermatitis & $3(5.1)$ & $8(10.0)$ & $11(7.9)$ & 0.4574 \\
\hline
\end{tabular}

${ }^{*} \mathrm{TRS}=$ troublesome respiratory symptoms.

$\dagger A B=$ Asthmatic bronchitis.

$\ddagger$ ICS use $1 \mathrm{y}=$ Use of inhaled corticosteroid during the first year of life.

§SABA use $1 \mathrm{y}=$ Use of short-acting inhaled beta-agonists during the first year of life.

ILTRA use $1 \mathrm{y}=$ Use of leukotriene receptor antagonist during the first year of life.

${ }^{\star *}$ Pneumonia $1 \mathrm{y}=$ Pneumonia treated with antibiotics during the first year of life. 
and clinical observations by a trained physician. Moreover, a biobank including plasma, serum, buffy coat, urine and stool samples collected on the cohort from birth to 6 years old exist.

Limitations include the relatively small cohort, especially when dividing into subgroups. Some of the lifestyle variables such as smoking during pregnancy are self-reported, and therefore might be underestimated. This has been addressed by collecting hair and urine samples to evaluate the long-term effect of exposures (eg, cotinine). Finally, the 6-year follow-up was complicated by the ongoing COVID-19 pandemic, which has restrained some participants from attending follow-up visits due to fear of containing coronavirus at the hospital. Still, it is too early to say whether this will impact follow-up attendance since many visits have been postponed until participants felt safe. The risk of losing attendance at follow-up visits due to many years interval between visits is also a limitation in this cohort.

Power analysis were performed before commencing the cohort; however, further analysis and substudies on this cohort were explorative.

\section{Author affiliations}

${ }^{1}$ Department of Paediatrics and Adolescence Medicine, Nordsjaellands Hospital, Hillerod, Denmark

${ }^{2}$ Department of Clinical Medicine, University of Copenhagen, Faculty of Health and Medical Science, Copenhagen, Denmark

${ }^{3}$ Department of Paediatrics and Adolescent Medicine, Rigshospitalet, Copenhagen, Denmark

${ }^{4}$ Department of Paediatric Cardiology, Rigshospitalet, Kobenhavn, Denmark ${ }^{5}$ Department of Pediatrics, H.C. Andersen Children's Hospital, Odense University Hospital, Odense, Denmark

Acknowledgements We dedicate this paper to the children and families in the AD-ON cohort.

Contributors IMJ, BJS and PA designed the AD-ON birth and neonatal cohort and follow-up at one year. BJS collected the neonatal and 1-year follow-up data. FEMG validated 1-year follow-up data. FEMG, IMJ, LA and KJ planned the data collection at 6-year follow-up. FEMG collected the 6-year follow-up data. All authors contributed to writing and reviewing the paper, have approved it for submission, and agree to be accountable for its content.

Funding The work on this cohort has been funded by Nordsjaellands Hospital Research Found, Children's Lung Foundation, Denmark, Mrs Olga Bryde Nielsen's Foundation, Lieutenant Harald Jensen and Wife's Foundation, Director Jacob Madsen and Wife Olga's Foundation, Carpenter Joergen Holm and Wife Elisa B. Hansen's memorial Foundation, Research Foundation Capital Region of Denmark, The Toyota Foundation, and A.P Moeller Foundation.

Disclaimer All authors contributed to writing and reviewing the paper, have approved it for submission, and agree to be accountable for its content. IMJ act as guarantor for this work. The study sponsors played no role in the study design, in the collection, analysis, interpretation of data, and in the decision to submit this or other cohort related papers for publication.

Competing interests None declared.

Patient consent for publication Not applicable.

Ethics approval The Copenhagen Capital Region Ethics Committee ID: H-42012-091 and $\mathrm{H}-19011004$. Participants gave informed consent to participate in the study before taking part.

Provenance and peer review Not commissioned; externally peer reviewed.

Data availability statement Data are available upon reasonable request. The data are still being analysed but can be shared upon request. Researchers interested in exploring or sharing the data or would be interested in copies of questionnaires used in this study can contact the principal investigator Dr Inger Merete Jørgensen (email: inger.merete.joergensen@regionh.dk).

Supplemental material This content has been supplied by the author(s). It has not been vetted by BMJ Publishing Group Limited (BMJ) and may not have been peer-reviewed. Any opinions or recommendations discussed are solely those of the author(s) and are not endorsed by BMJ. BMJ disclaims all liability and responsibility arising from any reliance placed on the content. Where the content includes any translated material, BMJ does not warrant the accuracy and reliability of the translations (including but not limited to local regulations, clinical guidelines, terminology, drug names and drug dosages), and is not responsible for any error and/or omissions arising from translation and adaptation or otherwise.

Open access This is an open access article distributed in accordance with the Creative Commons Attribution Non Commercial (CC BY-NC 4.0) license, which permits others to distribute, remix, adapt, build upon this work non-commercially, and license their derivative works on different terms, provided the original work is properly cited, appropriate credit is given, any changes made indicated, and the use is non-commercial. See: http://creativecommons.org/licenses/by-nc/4.0/.

ORCID iDs

Fanny Edit Maria Goth http://orcid.org/0000-0002-8904-4653

Birgitte Johanne Schmidt http://orcid.org/0000-0002-5866-5027

\section{REFERENCES}

1 Parikh K, Hall M, Mittal V, et al. Establishing benchmarks for the hospitalized care of children with asthma, bronchiolitis, and pneumonia. Pediatrics 2014;134:555-62.

2 Källén B, Finnström O, Nygren K-G, et al. Association between preterm birth and intrauterine growth retardation and child asthma. Eur Respir J 2013;41:671-6.

3 Noutsios GT, Floros J. Childhood asthma: causes, risks, and protective factors; a role of innate immunity. Swiss Med Wkly 2014;144:w14036.

4 Bui DS, Burgess JA, Lowe AJ, et al. Childhood lung function predicts adult chronic obstructive pulmonary disease and Asthma-Chronic obstructive pulmonary disease overlap syndrome. Am J Respir Crit Care Med 2017;196:39-46.

5 Shapiro-Mendoza CK, Lackritz EM. Epidemiology of late and moderate preterm birth. Semin Fetal Neonatal Med 2012;17:120-5.

6 Harrison MS, Goldenberg RL. Global burden of prematurity. Semin Fetal Neonatal Med 2016;21:74-9.

7 Narang I, Rosenthal M, Cremonesini D, et al. Longitudinal evaluation of airway function 21 years after preterm birth. Am J Respir Crit Care Med 2008;178:74-80.

8 Vollsæter M, Røksund OD, Eide GE, et al. Lung function after preterm birth: development from mid-childhood to adulthood. Thorax 2013;68:767-76.

9 Vrijlandt EJLE, Kerstjens JM, Duiverman EJ, et al. Moderately preterm children have more respiratory problems during their first 5 years of life than children born full term. Am J Respir Crit Care Med 2013;187:1234-40.

10 Caserta MT, Yang H, Bandyopadhyay S, et al. Measuring the Severity of Respiratory Illness in the First 2 Years of Life in Preterm and Term Infants. J Pediatr 2019;214:12-19.

11 Gijtenbeek RGP, Kerstjens JM, Reijneveld SA, et al. RSV infection among children born moderately preterm in a community-based cohort. Eur J Pediatr 2015;174:435-42.

12 Ricciardolo FLM, Sterk PJ, Gaston B, et al. Nitric oxide in health and disease of the respiratory system. Physiol Rev 2004;84:731-65.

13 Gao Y, Raj JU. Regulation of the pulmonary circulation in the fetus and newborn. Physiol Rev 2010;90:1291-335.

14 Parker TA, le Cras TD, Kinsella JP, et al. Developmental changes in endothelial nitric oxide synthase expression and activity in ovine fetal lung. Am J Physiol Lung Cell Mol Physiol 2000;278:L202-8.

15 Chang D, Yao W, Tiller CJ, et al. Exhaled nitric oxide during infancy as a risk factor for asthma and airway hyperreactivity. Eur Respir $J$ 2015;45:98-106.

16 Elphick HE, Demoncheaux EA, Ritson S, et al. Exhaled nitric oxide is reduced in infants with cystic fibrosis. Thorax 2001;56:151-2.

17 Karadag B, James AJ, Gültekin E, et al. Nasal and lower airway level of nitric oxide in children with primary ciliary dyskinesia. Eur Respir J 1999;13:1402-5.

18 Chawes BLK, Buchvald F, Bischoff AL, et al. Elevated exhaled nitric oxide in high-risk neonates precedes transient early but not persistent wheeze. Am J Respir Crit Care Med 2010;182:138-42. 
19 Usemann J, Fuchs O, Anagnostopoulou P, et al. Predictive value of exhaled nitric oxide in healthy infants for asthma at school age. Eur Respir J 2016;48:925-8.

20 Roiha HL, Kuehni CE, Zanolari M, et al. Alterations of exhaled nitric oxide in pre-term infants with chronic lung disease. Eur Respir $J$ 2007;29:251-8.

21 Williams O, Dimitriou G, Hannam S, et al. Lung function and exhaled nitric oxide levels in infants developing chronic lung disease. Pediatr Pulmonol 2007;42:107-13.

22 Liu L-J, Gao X-R, Wu P-P, et al. Exhaled nitric oxide in neonates with or without hypoxemic respiratory failure. World J Emerg Med 2011;2:195-200.

23 Leipälä JA, Williams O, Sreekumar S, et al. Exhaled nitric oxide levels in infants with chronic lung disease. Eur J Pediatr 2004;163:555-8.

24 Fuchs $\mathrm{O}$, Latzin $\mathrm{P}$, Thamrin $\mathrm{C}$, et al. Normative data for lung function and exhaled nitric oxide in unsedated healthy infants. Eur Respir $J$ 2011;37:1208-16.

25 Greer FR. Fat-soluble vitamin supplements for enterally fed preterm infants. Neonatal Netw 2001;20:7-11.

26 Shenai JP, Chytil F. Vitamin A storage in lungs during perinatal development in the rat. Biol Neonate 1990;57:126-32.

27 Nguyen M, Trubert CL, Rizk-Rabin M, et al. 1,25-Dihydroxyvitamin D3 and fetal lung maturation: immunogold detection of VDR expression in pneumocytes type II cells and effect on fructose 1,6 bisphosphatase. J Steroid Biochem Mol Biol 2004;89-90:93-7.

28 Damera G, Fogle HW, Lim P, et al. Vitamin D inhibits growth of human airway smooth muscle cells through growth factor-induced phosphorylation of retinoblastoma protein and checkpoint kinase 1. Br J Pharmacol 2009;158:1429-41.

29 Devereux G, Litonjua AA, Turner SW, et al. Maternal vitamin D intake during pregnancy and early childhood wheezing. Am J Clin Nutr 2007;85:853-9.

30 Camargo CA, Rifas-Shiman SL, Litonjua AA, et al. Maternal intake of vitamin $D$ during pregnancy and risk of recurrent wheeze in children at 3 Y of age. Am J Clin Nutr 2007;85:788-95.

31 May C, Williams O, Milner AD, et al. Relation of exhaled nitric oxide levels to development of bronchopulmonary dysplasia. Arch Dis Child Fetal Neonatal Ed 2009;94:F205-9.

32 Julious SA. Sample size of 12 per group rule of thumb for a pilot study. Pharm Stat 2005;4:287-91.

33 Ma Y, Mazumdar M, Memtsoudis SG. Beyond repeated-measures analysis of variance: advanced statistical methods for the analysis of longitudinal data in anesthesia research. Reg Anesth Pain Med 2012;37:99-105.

34 Schoenfeld D. Statistical considerations for pilot studies. Int J Radiat Oncol Biol Phys 1980;6:371-4.

35 Hermann C, De Fine Olivarius N, Høst A, et al. Prevalence, severity and determinants of asthma in Danish five-year-olds. Acta Paediatr 2006;95:1182-90.

36 Morata-Alba J, Romero-Rubio MT, Castillo-Corullón S, et al. Respiratory morbidity, atopy and asthma at school age in preterm infants aged 32-35 weeks. Eur J Pediatr 2019;178:973-82.

37 Leps C, Carson C, Quigley MA. Gestational age at birth and wheezing trajectories at 3-11 years. Arch Dis Child 2018;103:1138-44

38 Apgar V. A proposal for a new method of evaluation of the newborn infant. Anesthesia \& Analgesia 1953;32:260-7.

39 Statens serum institute. Childhood vaccination programme, 2019. Available: https://en.ssi.dk/vaccination/the-danish-childhoodvaccination-programme

40 Pearce N, Weiland S, Keil U, et al. Self-reported prevalence of asthma symptoms in children in Australia, England, Germany and
New Zealand: an international comparison using the ISAAC protocol. Eur Respir J 1993;6:1455-61.

41 Liu AH, Zeiger RS, Sorkness CA, et al. The childhood asthma contro test: retrospective determination and clinical validation of a cut point to identify children with very poorly controlled asthma. J Allergy Clin Immunol 2010;126:267-73.

42 Wang Z, Zolnik CP, Qiu Y, et al. Comparison of fecal collection methods for microbiome and metabolomics studies. Front Cell Infect Microbiol 2018;8:301.

43 Howie SRC. Blood sample volumes in child health research: review of safe limits. Bull World Health Organ 2011;89:46-53.

44 American Thoracic Society, European Respiratory Society. ATS/ ERS recommendations for standardized procedures for the online and offline measurement of exhaled lower respiratory nitric oxide and nasal nitric oxide, 2005. Am J Respir Crit Care Med 2005;171:912-30.

45 Schmidt BJ, Reim PS, Jensen AK, et al. Tidal breath eNO measurements in a cohort of unsedated hospitalized neonates-A method validation. Pediatr Pulmonol 2018;53:762-71.

46 Lødrup-Carlsen KC, Carlsen $\mathrm{KH}$. Lung function in awake healthy infants: the first five days of life. Eur Respir J 1993;6:1496-500.

47 Frey U, Stocks J, Coates A, et al. Specifications for equipment used for infant pulmonary function testing. ERS/ATS Task force on standards for infant respiratory function testing. European respiratory Society/ American thoracic Society. Eur Respir J 2000;16:731-40.

48 Beydon N, Davis SD, Lombardi E, et al. An official American thoracic Society/European respiratory Society statement: pulmonary function testing in preschool children. Am J Respir Crit Care Med 2007;175:1304-45

49 Miller MR, Hankinson J, Brusasco V, et al. Standardisation of spirometry. Eur Respir J 2005;26:319-38.

50 Parasuraman S, Walker S, Loudon BL, et al. Assessment of pulmonary artery pressure by echocardiography-A comprehensive review. Int J Cardiol Heart Vasc 2016;12:45-51.

51 Lopez L, Colan SD, Frommelt PC, et al. Recommendations for quantification methods during the performance of a pediatric echocardiogram: a report from the pediatric measurements writing group of the American Society of echocardiography pediatric and congenital heart disease Council. J Am Soc Echocardiogr 2010;23; :465-95. quiz.

52 Sonnappa S, Bastardo CM, Wade A, et al. Symptom-pattern phenotype and pulmonary function in preschool wheezers. J Allergy Clin Immunol 2010;126:519-26.

53 Schmidt BJ, Reim PS, Pedersen OF, et al. A possible way to assess tidal exhaled nitric oxide in neonates and infants treated with nasal continuous positive airway pressure. Acta Paediatr 2018;107:557-9.

54 Schmidt BJ. Tidal exhaled nitric oxide in neonates - a longitudinal study. University of Copenhagen, 2017.

55 Goth FEM, Schmidt BJ, Green K, et al. Neonatal FeNO, risk factors, and respiratory morbidity in infants: a cohort study. Pediatr Pulmonol 2021;56:3174-82.

56 Bisgaard $\mathrm{H}$. The Copenhagen prospective study on asthma in childhood (COPSAC): design, rationale, and baseline data from a longitudinal birth cohort study. Ann Allergy Asthma Immunol 2004;93:381-9.

57 Fuchs O, Latzin P, Kuehni CE, et al. Cohort profile: the Bern infant lung development cohort. Int J Epidemiol 2012;41:366-76.

58 Marsál K, Persson PH, Larsen T, et al. Intrauterine growth curves based on ultrasonically estimated foetal weights. Acta Paediatr 1996;85:843-8. 